\title{
Best Bets: Additional Funding for Family Planning-International evidence on financing of family planning
}

Zeba Sathar

Population Council

Follow this and additional works at: https://knowledgecommons.popcouncil.org/departments_sbsr-rh

Part of the Health Services Research Commons How does access to this work benefit you? Let us know!

\section{Recommended Citation}

Sathar, Zeba. 2020. "Best Bets: Additional Funding for Family Planning-International evidence on financing of family planning," brief. Islamabad: Population Center Pakistan. 


\section{Acknowledgements:}

The author gratefully acknowledges research assistance provided by Mr. Sabahat Hussain - Program Officer, Population Council, analysis by Mr. Maqsood Sadiq - Deputy Program Manager, Population Council and comments received from Mr Farooq Azam - CEO, Population Center Pakistan and Dr. Ali M. Mir - Population Council.

\section{Best Bets: Additional Funding for Family Planning}

\section{International Evidence on Financing of Family Planning}

\section{Investment Needs and Gaps}

In 2018, bilateral family planning (FP) funding from donor governments reached $\$ 1.5$ billion, 1 the highest level since the London Summit in 2012, even after accounting for inflation and exchange rate fluctuations. However, a gap of $\$ 1$ billion remains with regard to the pledge at the Summit of $\$ 2.5$ billion. Family planning funding accounted for only $9 \%$ of all sexual and reproductive health and rights (SRHR) funding by donors in 2017.,3,4

Among the 1.9 billion women of reproductive age (15-49 years) living globally in 2019, 1.1 billion need family planning. Of these, 842 million are already using modern methods of contraception but the remaining 270 million have unmet need: they want to avoid a pregnancy but are not using a modern contraceptive method.

The majority of these women-218 million-reside in low- and middle-income countries (LMICs) where about half $(49 \%)$ of the pregnancies that occur every year, i.e., 111 million, are unintended.5,6,7 And yet the LMICs in particular have huge financing gaps in family planning provision.
According to recent estimates by the Guttmacher Institute, ${ }^{8}$ the annual cost of contraceptive services for the $\mathbf{7 0 5}$ million current users of modern contraceptive methods in these countries is $\$ \mathbf{\$ 7}$ billion, which works out to be $\$ 10.10$ per capita. It is estimated that donors account for $\mathbf{1 0} \%$ of FP funding in LMICs, while country governments contribute $8 \% ; 82 \%$ of expenses are met out of pocket by individuals. ${ }^{9}$ If LMICs were to expand FP services to address the unmet need of 218 million women, the total cost would go up to $\$ 12.6$ billion. This presents a funding gap of $\$ 5.5$ billion.

A package of care that meets all women's needs for modern contraception, pregnancy-related services, and newborn care would cost $\$ 66.6$ billion annually in LMICs, or approximately $\$ 10.30$ per capita applied to a population of 6.5 billion in LMICs. ${ }^{10}$ The average cost of such a combined package varies across regions and country-income categories, from $\$ 17.93$ per capita in Africa to $\$ 5.67$ in Asia. ${ }^{11}$ 


\section{Benefits of Investments}

Current investments in contraceptive and pregnancy-related care averted at least 387,000 maternal deaths in LMICs in 2019. Fully meeting the needs for contraceptive and pregnancy-related care would avert an additional 186,000 maternal deaths annually and would result in 76 million fewer unintended pregnancies, 25 million fewer unsafe abortions, and 21 million fewer unplanned births in LMICs. ${ }^{12}$

There is additional international evidence of benefits extending to other areas and sectors of development that shows investment in family planning to be cost-effective. The major findings vary: according to one model run for 16 developing countries, the benefit-cost ratio (BCR) of investing in satisfying unmet need for family planning ranges from 30 to 50 through reduced maternal and infant mortality, and 60 to 100 through income growth. ${ }^{13}$

In Kenya, family planning expenditures of $\$ 71$ million during 2005-15 was associated with social sector cost savings of $\$ 271$ million-a BCR of close to $4: 1 .^{14}$ The social and economic benefits from delaying childbearing in 106 countries have been estimated at $\$ 22$ billion in 2015 and $\$ 566$ billion in $2030 .{ }^{15}$ According to estimates by the United Nations, every dollar spent on contraception can save two to six dollars through reduced numbers of people needing other public services, such as immunization, health care, education, and sanitation. ${ }^{16}$

\section{The Case for Greater Investment in Family Planning in Pakistan}

In Pakistan, concern for high fertility led the Council of Common Interests (CCI) to take important decisions to accelerate implementation of universal access to family planning in 2018. ${ }^{17}$ Low levels of financing for FP were identified as a major concern, and the following decisions made in this regard:

1. The federal government will create a five-year nonlapsable Special Fund for reducing the population growth rate, with annual allocation of Rs. 10 billion (\$67 million in 2019 equivalent). The Fund shall be set up exclusively from federal resources, without any cut from provincial funds. The Fund will:

a. Meet, for 5 years, $50 \%$ of the amount of additional locations made by the provinces for procurement of contraceptive commodities over and above the budget provision of Fiscal Year 2018-19;

b. Meet, for 5 years, $50 \%$ of the cost of increasing the Lady Health Worker (LHW) force to achieve 100\% coverage of doorstep services in rural and peri-urban areas; and c. Support innovative approaches by the federal and provincial governments to reach poor and marginalized populations to reduce population growth and increase the contraceptive prevalence rate (CPR).

2. Federal and provincial Population and Health budgets for $\mathrm{FP} /$ reproductive health $(\mathrm{RH})$ will be doubled over the next two years and protected from reallocation to other programs and departments while ensuring timely releases.

3. Donor financing to non-governmental organizations (NGOs) and private sector organizations involved in FP/RH will be streamlined through an effective coordination mechanism.

4. The corporate sector will allocate corporate social responsibility (CSR) funds for family planning services and advocacy.

There is a universal realization that while there may be serious gaps in funding for all areas of reproductive health, family planning is particularly neglected. Funding for family planning and its measurement continues to slip through the cracks, even when reproductive, maternal, newborn, and child nutrition and health (RMNCNH) expenditures are tracked. ${ }^{18}$

\section{Cost of Current Levels of FP and MNH Services}

There is no systematic way to extract family planning spending from national accounting systems or budgets in Pakistan. Annual levels of spending on family planning have largely been based on guesstimates as there is no direct budget line in public accounts reporting (through the Project to Improve Financial Reporting and Auditing [PIFRA]) that allows us to track expenditures by the government on FP supplies and services. The few health financing documents that do exist for Pakistan, such as National Health Accounts ${ }^{19}$ or reports on "Costing Essential Package of Health Services," $20,21,22$ are limited in scope and do not separately cover family planning or the other individual $\mathrm{RMNCH}$ indictors recommended by the World Health Organization (WHO). ${ }^{23}$ This makes it particularly difficult to estimate FP expenditure by health programs outside of the Population Welfare program, which is the only public sector program that exclusively delivers FP services.

Recently however, an important additional source of FP expenditure data has been revived in the country in the form of the Netherlands Interdisciplinary Demographic Institute (NIDI) survey. Traditionally, NIDI surveys collect data on family planning expenditures through a questionnaire sent out to individual governments. They 
provide estimates of spending on family planning as self-reported by the federal, provincial, and regional governments, including amounts spent on rent, contraceptive services, salaries, and administration in particular. The NIDI survey was conducted by the Population Council and United Nations Population Fund (UNFPA) for financial years 2018 and 2019, drawing on provincial and federal governments' reporting on expenditures on FP in these periods.

Data from the 2018 NIDI survey were utilized in a study by the Population Council and Guttmacher Institute to estimate the volume and nature of spending on family planning and funding gaps in Pakistan. The methodology of this study was based on Guttmacher Institute's well recognized Adding It Up methodologies published in 2016 and 2018. 24,25 Costs of contraceptive services and maternal and newborn health care were estimated using an ingredient-based costing method based on international sources and Pakistani cost data. For each contraceptive method or health care intervention, we combined the direct costs (in 2017 US dollars) of drugs, supplies and materials, labor, and hospitalization, with the indirect costs (also known as programs and systems costs), which include management, infrastructure, communications and outreach, to arrive at an annual cost of protection against unintended pregnancy for each woman receiving pregnancy-related medical care.

This approach permitted us to arrive at a well-constructed measure of the estimate of the "worth equivalent" of services required to match the current modern contraceptive prevalence rate and the level of maternal health services being availed in 2017. In ways, this can be regarded as the bottom-line estimate based on public sector costs of the system. It excludes any additional costs when services are rendered and received through the private sector, ${ }^{26}$ where prices are likely to be much higher. And above all it excludes all the out-of-pocket expenditures that are likely to be exorbitant based on data available for maternal health expenses. ${ }^{27}$

Table 1: Estimated costs of current level of family planning and maternal and neonatal health services in Pakistan, by province/region, 2017 (\$)

\begin{tabular}{|l|c|c|c|c|c|c|}
\hline & $\begin{array}{c}\text { Annual cost } \\
\text { of FP } \\
\text { services } \\
\text { (millions) }\end{array}$ & $\begin{array}{c}\text { Annual cost } \\
\text { of MNH } \\
\text { services } \\
\text { (millions) }\end{array}$ & $\begin{array}{c}\text { Annual cost } \\
\text { of FP+MNH } \\
\text { services } \\
\text { (millions) }\end{array}$ & $\begin{array}{c}\text { Per capita } \\
\text { cost of } \\
\text { FP services }\end{array}$ & $\begin{array}{c}\text { Per capita } \\
\text { cost of MNH } \\
\text { services }\end{array}$ & $\begin{array}{c}\text { Per capta cost of } \\
\text { FP+MNH services }\end{array}$ \\
\hline Punjab & 42.0 & 752.3 & 794.2 & 0.38 & 6.84 & 7.22 \\
\hline Sindh & 17.7 & 282.7 & 300.4 & 0.37 & 5.90 & 6.27 \\
\hline KPK & 13.8 & 111.9 & 125.8 & 0.45 & 3.67 & 4.12 \\
\hline Balochistan & 3.1 & 21.6 & 24.7 & 0.25 & 1.75 & 2.00 \\
\hline Gilgit-Baltistan & 0.7 & 5.6 & 6.3 & 0.44 & 3.73 & 4.17 \\
\hline ICT & 1.1 & 13.3 & 14.4 & 0.54 & 6.63 & 7.18 \\
\hline FATA & 1.4 & 12.2 & 13.6 & 0.29 & 2.44 & 2.72 \\
\hline AJK & 1.2 & 18.4 & 19.5 & 0.29 & 4.54 & 4.83 \\
\hline Pakistan & 80.9 & $1,217.9$ & $1,298.9$ & 0.38 & 5.71 & 6.09 \\
\hline
\end{tabular}

AJK=Azad Jammu and Kashmir, FATA=Federally Administered Tribal Areas, FP= family planning, ICT=Islamabad Capital Territory, $\mathrm{KP}=$ Khyber Pakhtunkhwa, MNH=maternal and newborn health care.

NOTES: Maternal and newborn health care includes interventions related to antenatal care; labor, delivery, and postpartum care; newborn care; and post-abortion care. Numbers may not add to totals (here or in the text) because of rounding.

The costs associated with MNH are indeed more extensive than FP, particularly for deliveries. However, it should be borne in mind that a large proportion of current MNH costs are due to unwanted pregnancies. The government and public are thus paying a heavy price for failure to ensure universal access to modern contraceptive services, which are much cheaper. 


\section{Gaps in Funding for Full FP and MNH Services}

As the next step in our analysis, we assessed the costs that would be incurred if provision of FP and MNH services were expanded to eliminate all unmet need. In the context of family planning, we assumed that all women with demand for family planning in 2017 were provided modern contraceptive services (including the large numbers of women using traditional methods, who are unaccounted for in the current cost estimates presented above). For MNH services, we added those women who were not getting the full level of care, in terms of antenatal and postnatal visits, delivery in institutions, and neonatal care for their newborns. The results are presented in Table 2.

Table 2: Estimated costs of required level of family planning and maternal and neonatal health services in Pakistan, by province/region, 2017 (\$)

\begin{tabular}{|l|c|c|c|c|c|c|}
\hline & $\begin{array}{c}\text { Required } \\
\text { Cost of FP } \\
\text { Services }\end{array}$ & $\begin{array}{c}\text { Required } \\
\text { Cost of MNH } \\
\text { Services }\end{array}$ & $\begin{array}{c}\text { Required } \\
\text { Cost of } \\
\text { FP+MNH } \\
\text { Services }\end{array}$ & $\begin{array}{c}\text { Required Per } \\
\text { capita cost of } \\
\text { FP services }\end{array}$ & $\begin{array}{c}\text { Required Per } \\
\text { capita cost of } \\
\text { MNH services }\end{array}$ & $\begin{array}{c}\text { Required Per } \\
\text { capita cost } \\
\text { of FP+MNH } \\
\text { services }\end{array}$ \\
\hline Punjab & 85.7 & 822.4 & 908.1 & 0.78 & 7.48 & 8.26 \\
\hline Sindh & 36.1 & 362.2 & 398.3 & 0.75 & 7.56 & 8.32 \\
\hline KP & 31.5 & 267.1 & 298.7 & 1.03 & 8.75 & 9.79 \\
\hline Balochistan & 9.3 & 93.3 & 102.6 & 0.75 & 7.56 & 8.31 \\
\hline Gilgit-Baltistan & 1.5 & 11.7 & 13.1 & 0.97 & 7.77 & 8.74 \\
\hline ICT & 2 & 13.5 & 15.5 & 1.01 & 6.71 & 7.73 \\
\hline FATA & 4.2 & 49.9 & 54 & 0.83 & 9.97 & 10.8 \\
\hline AJK & 3.2 & 29 & 32.2 & 0.78 & 7.17 & 7.95 \\
\hline Pakistan & 173.5 & $1,649.1$ & $1,822.6$ & 0.81 & 7.73 & 8.54 \\
\hline
\end{tabular}

AJK=Azad Jammu and Kashmir, FATA=Federally Administered Tribal Areas, FP= family planning, ICT=Islamabad Capital Territory, KP=Khyber Pakhtunkhwa, MNH=maternal and newborn health care.

When the estimated actual costs (Table 1) are compared with estimates of required levels of funding (Table 2), the spending gap for FP is revealed to be $\$ 93$ million or $\$ 0.43$ per capita, which is slightly over double the current expenditure. The gap in MNH spending is over four times larger, at \$421 million or \$2.0 per capita. In both absolute and per capita terms, the MCH investment gap eclipses the additional funding requirement for FP, which is much more affordable (Figure 1).

Figure 1: Per capita current spending, required spending, and the gap in funding for full family planning and maternal and newborn health care in Pakistan, 2017 (US\$)

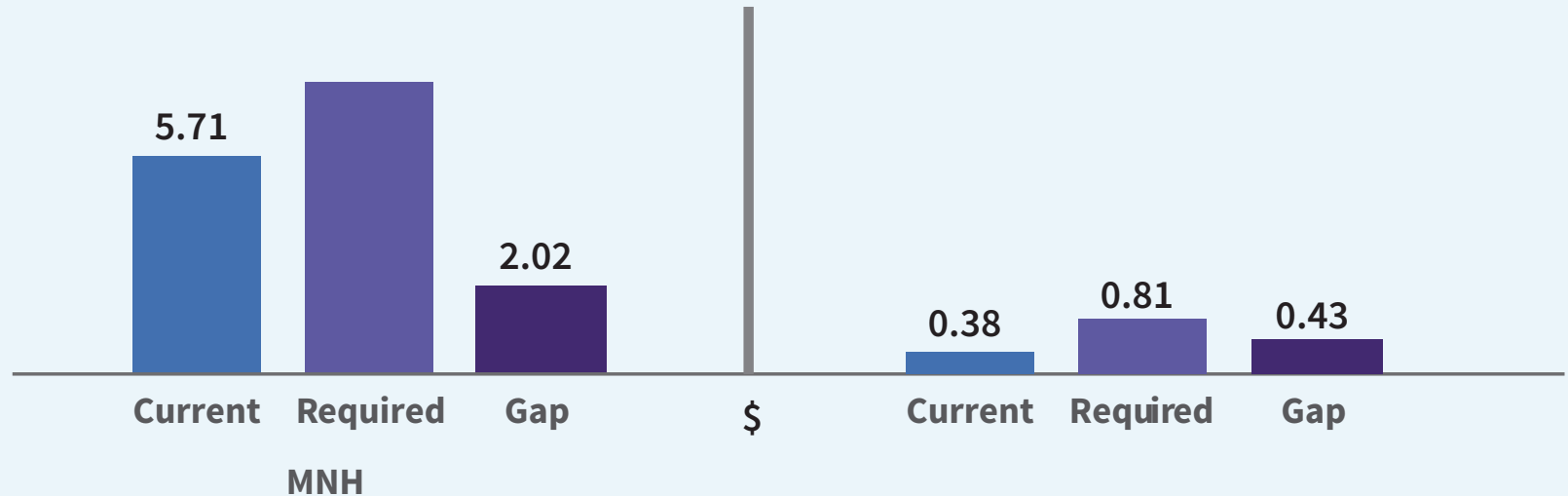

Source: Sundaram, A., Hussain, R., Sathar, Z., Hussain, S., Pliskin, E., \& Weissman, E. (2019). Adding It Up: Costs and Benefits of Meeting the Contraceptive and Maternal And Newborn Health Needs of Women in Pakistan, New York: Guttmacher Institute. 


\section{Rationale for Additional Spending on Family Planning}

Not only is it more affordable to bridge the funding gap for FP than for $\mathrm{MNH}$, but doing so would also reduce the amount of additional funding required for full $\mathrm{MNH}$ care, by eliminating or reducing millions of unwanted and mistimed pregnancies. This is the strongest rationale for increasing investment in family planning, and it provides a solid common platform for advocacy and justification for additional spending.
As illustrated in Figure 2, filling in the FP funding gap to ensure that all need for family planning is met with modern contraceptive services would result in at least 3 million fewer pregnancies in Pakistan every year. This would lead to huge savings on associated MNH costs, specifically antenatal and postpartum care; the delivery and neonatal costs of unwanted births; and the numbers of abortions and related abortion and post-abortion care.

Figure 2: Estimated number of unplanned births, miscarriages, and abortions from unintended pregnancies in Pakistan in three scenarios of modern contraceptive prevalence (in millions)

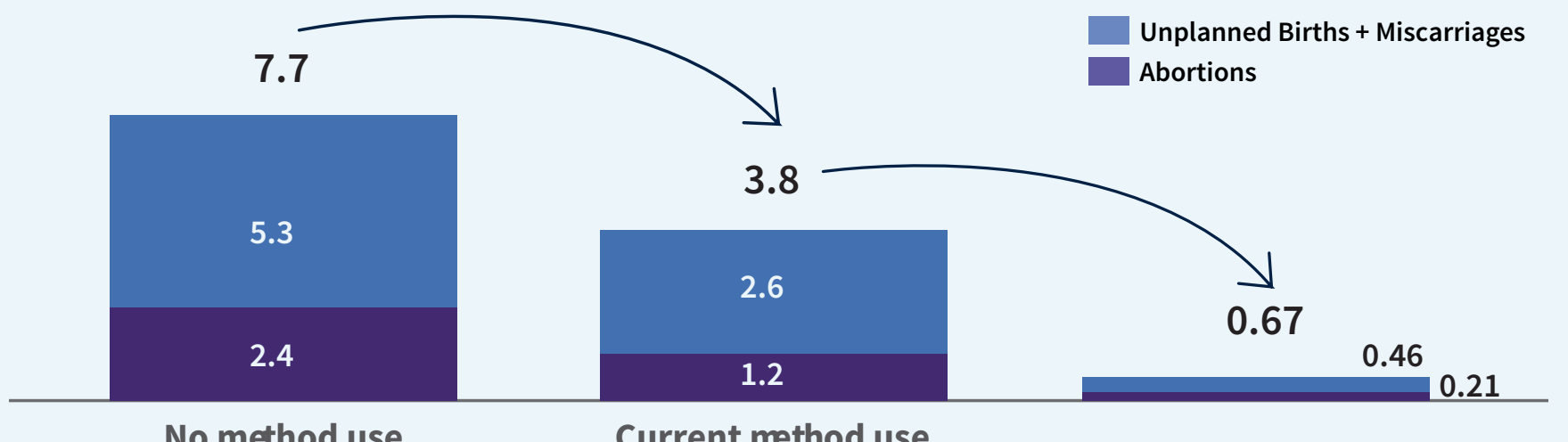

Source: Pakistan Demographic and Health Survey (PDHS) 2017-2018

Note: Private sector source includes providers, pharmacies, medical stores, and shops

The additional ask for family planning is only one fifth of that for completing the full needs for MNH. Furthermore, a substantial percentage of current spending and additional funding estimated will go towards the needs of $\mathrm{MNH}$ care of unwanted pregnancies, which family planning spending can avert altogether.

Another extremely strong rationale for prioritizing additional family planning expenditure is the potential it holds for saving the lives of mothers. Further reduc- tions in maternal mortality from the current (2007-2019) level of 186 per 100,000 live births will not be possible at current levels of fertility, especially unwanted fertility. An MMR of 70 per 100,000, as targeted under the Sustainable Development Goals (SDGs), will only be achievable if we can reduce unmet need for family planning and raise contraceptive prevalence. Investments in FP comprise an especially important contribution towards meeting many of the SDGs, but particularly reducing maternal mortality, in Pakistan.

\section{Recommendations for Better Financing and More Effective Spending}

\section{Fund the Public Health Sector for Family Planning}

Public sector family planning services are mainly delivered separately in each province through the facilities of the Population Welfare Department (PWD) and the Department of Health (DOH), as well as the latter's Lady Health Workers (LHWs). The Population Welfare program was introduced in the 1960s to focus on provision of family planning services. This introduced a duality in the structure of the public service delivery of family planning in which the DOH did not consider provision of family planning services a vital priority. Over time, minor adjustments have been made in the system, but the two departments essentially continue to operate in silos, despite the strong interlinkages between family planning and other, especially maternal, health outcomes, and the potential to operate much more efficiently by joining forces. Data from the latest NIDI survey clearly show (Figure 3) that a bulk of public sector spending on family planning in Pakistan is being carried out by the Population Welfare programs, and within that spending, the lion's share $(66 \%)$ is going to salaries. Hardly $5 \%$ is spent on contraceptives and logistics and only $2 \%$ on other program efforts. 
Figure 3: Breakdown of Public Family Planning Expenditure (\$148 million) in Pakistan by Department and Expense Category, 2018-19

\section{Share of Departments}

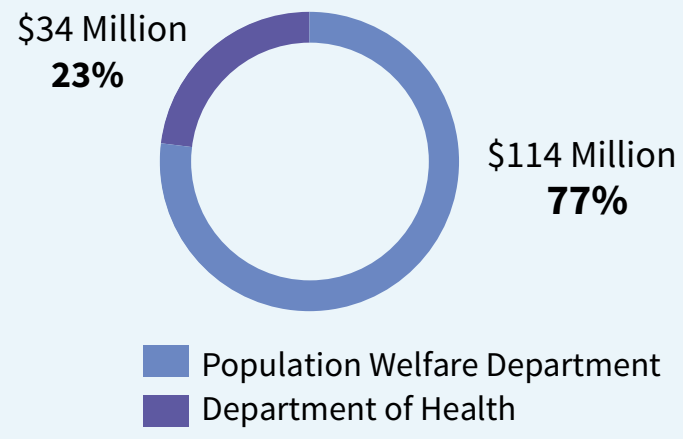

\section{Share of Expense Categories}

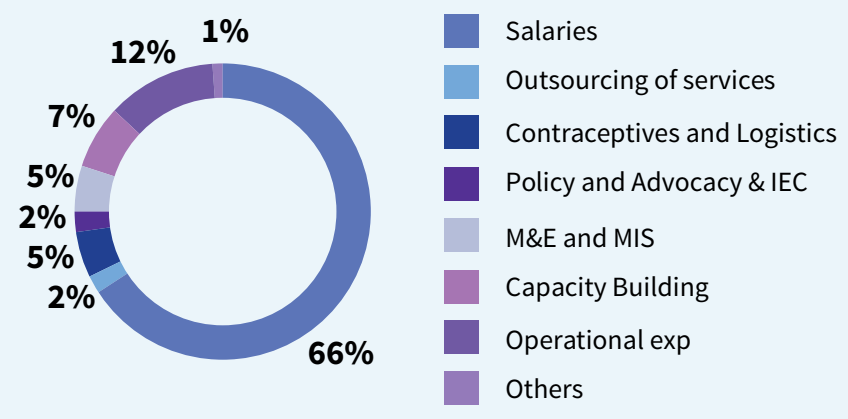

Source: Population Council, the Netherlands Interdisciplinary Demographic Institute (NIDI) Survey, 2018-19

The evidence shows that the current service delivery mode is inefficient. The case has been made to enhance efficiency in FP service delivery by integrating services provided by the $\mathrm{DOH}$ and PWD. ${ }^{28}$ It makes sense for providers of maternal, child and general family health services to also share the task of FP service provision as it is closely related to the health outcomes they are concerned with. Moreover, they have more opportunities to interact with current and especially potential FP users than those service providers who only provide FP services. The 'mainstream' health service providers working at $\mathrm{DOH}$ facilities represent a largely untapped resource for encouraging more couples to initiate family planning, and to support those who need help in continuing the use of modern methods. However, the necessary reforms for task sharing have not been made and there is reluctance by both departments to work together because of possible challenges, such as complications in sharing resources, loss of jobs, and increased workloads.

One of the manifestations of limited attention and funding for FP services at public facilities is the large proportions of women reporting private health facilities as their source of such services. Figure 4 shows the striking finding that even in the poorest income quintile, as many as $30.8 \%$ of married women utilize private sources. (Conversely, it is worth noting that as many as $27.5 \%$ of married women in the richest quintile utilize public sources, which are intended for the poorer women.)

Figure 4: Utilization of public, private, and other sources of family planning services by income quintile by currently married women of reproductive age (15-49 years), 2018

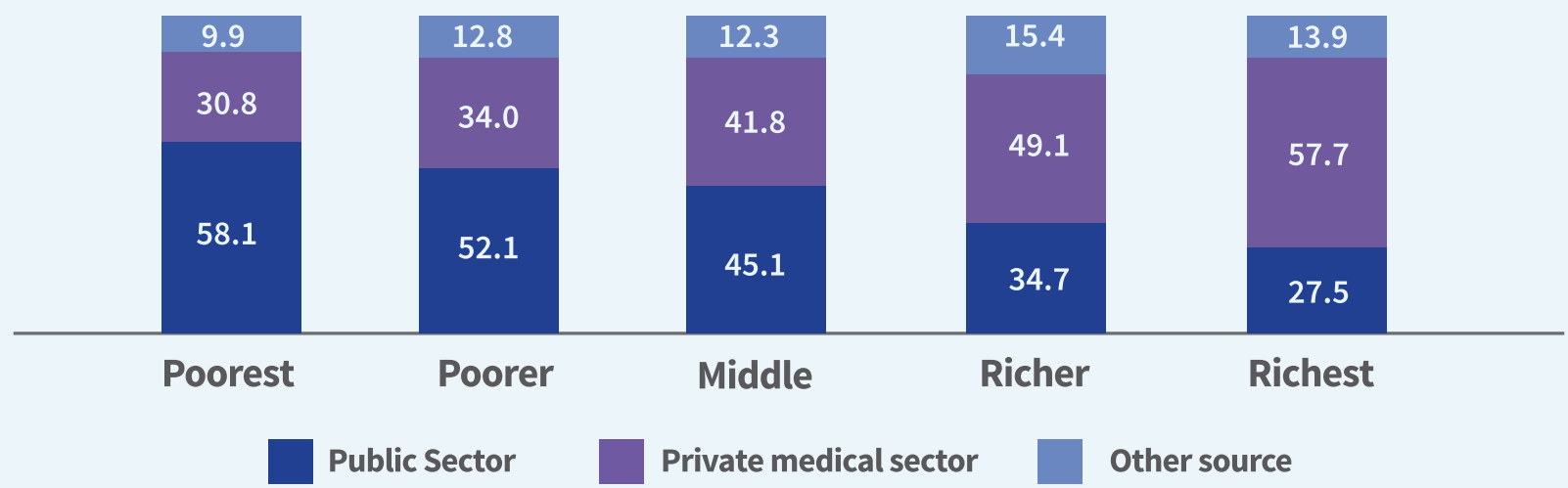


Our proposal is that the bulk of the additional spending on family planning should go to the DOH and the Lady Health Worker Program to ensure more complete coverage of LHWs and Community Midwives (CHW); support task shifting; introduce new job descriptions; and to enable the $\mathrm{DOH}$ to purchase its own share of contraceptives. This is aligned with the goal of the $\$ 67$ million Population Fund proposed in the CCI decisions to stimulate a higher-level health response by "matching" costs of additional LHWs and additional purchase of contraceptives by the provinces.

The evidence-based recommendation to immediately make contraceptive services an essential part of public health efforts to improve maternal neonatal outcomes and family health more generally is indisputable. While the CCI recommendations along with many health sector strategies do underscore this approach, and notifications for the mandatory delivery of family planning services in health outlets have been issued, inclusion of FP in $\mathrm{MNH}$ services remains minimal or suboptimal on the ground..$^{29}$ Contraceptive services continue to be seen as standalone services, and the aims of the Population Welfare and Public Health programs are seen as divorced from each other. As we have argued above, investing in family planning could achieve huge savings of MNH expenses by preventing unintended pregnancies. Highlighting these financial implications and directing additional FP funding towards the DOH rather than the PWD may finally motivate greater ownership of family planning by the mainstream public health system, paving the way for a merging of the two departments for greater efficiency.

\section{Channel additional spending to the most under-resourced regions}

In the Adding It Up study, the Population Council and Guttmacher Institute found that the largest share of expenditure on FP in Pakistan is being made in Punjab, at almost $\$ 42$ million, followed by $\$ 17.6$ million in Sindh, and \$13.8 million in Khyber Pakhtunkhwa (KP). The rest of the regions have notably smaller shares, with particularly small amounts being spent on family planning services in the regions of Gilgit-Baltistan (GB) and the Federally Administered Tribal Areas (FATA) especially. Per capita expenditure on FP is relatively higher in the Islamabad and Azad Jammu and Kashmir (AJK) regions.
More importantly, as Table 3 shows, the funding gaps are largest in the smaller provinces-the very ones that also do not have the budgets to allocate to the health sector and to reproductive health care needs. The combined gap per capita for $\mathrm{MNH}$ and FP is as small as $\$ 1.04$ in Punjab and \$2.0 in Sindh; in contrast KP and Balochistan have almost three times the deficit at $\$ 6$ per capita. Among the regions, Islamabad has the smallest gap at $\$ 0.55$ per capita and is already spending an adequate amount, but the gap is very wide in FATA.

Table 3: The gap in funding for full family planning and maternal and newborn health care in Pakistan, by province/ region, 2017 (\$)

\begin{tabular}{|l|c|c|c|c|c|c|}
\hline \multirow{2}{*}{ Region } & \multicolumn{3}{|c|}{ Total Funding Gaps (in millions) } & \multicolumn{3}{c|}{ Total Per Capita Funding Gap } \\
\cline { 2 - 7 } & FP & MNH & FP+MNH & FP & MNH & FP+MNH \\
\hline Punjab & 43.7 & 70.1 & 113.9 & 0.40 & 0.64 & 1.04 \\
\hline Sindh & 18.5 & 79.5 & 98.0 & 0.39 & 1.66 & 2.05 \\
\hline KP & 17.7 & 155.2 & 172.9 & 0.58 & 5.09 & 5.67 \\
\hline Balochistan & 6.2 & 71.7 & 77.9 & 0.50 & 5.81 & 6.31 \\
\hline Gilgit-Baltistan & 0.8 & 6.1 & 6.9 & 0.53 & 4.04 & 4.57 \\
\hline ICT & 0.9 & 0.2 & 1.1 & 0.47 & 0.08 & 0.55 \\
\hline FATA & 2.7 & 37.7 & 40.4 & 0.55 & 7.53 & 8.08 \\
\hline AJK & 2.0 & 10.6 & 12.6 & 0.49 & 2.63 & 3.12 \\
\hline Pakistan & 92.6 & 431.2 & 523.7 & 0.43 & 2.02 & 2.46 \\
\hline
\end{tabular}

AJK=Azad Jammu and Kashmir, FATA=Federally Administered Tribal Areas, ICT=Islamabad Capital Territory, KP=Khyber Pakhtunkhwa.

NOTES: Maternal and newborn health care includes interventions related to antenatal care; labor, delivery and postpartum care; newborn care and post abortion care. Numbers may not add to totals (here or in the text) because of rounding. 
Our second recommendation is to utilize additional funding to fill the gaps in under-resourced regions, which have more limited budgets and stringent fiscal space. These regions are, clearly, Balochistan, FATA, and Gilgit-Baltistan. While AJK and GB both show extraordinarily strong political commitment and readiness to provide family planning services, they are dependent on federal sources. Their funding gaps, though not as large as those of some of the provinces due to their smaller population sizes, are nevertheless substantial for their budgets. The regions are unlikely to acquire the amounts required and most definitely need to be prioritized for additional allocations.

The expenditure data in Table 1 depict the worth of contraceptive services rendered and are therefore also reflective of performance in service delivery. In terms of per capita spending on FP, there is not a huge difference between Sindh and Punjab, but KP and ICT and GB are spending more, while Balochistan, FATA, and AJK are spending far less.

The important message for federal policy makers and international partners is to give Grant in Aid to the underserved areas, and also focus on them in their projects. This may be against the current grain of thinking, which favors serving larger numbers with unmet need in Punjab, Sindh, and KP. Islamabad as a capital territory seems well positioned but needs to honor its federal commitment and meet its responsibility to the areas covered under the federal budget, especially AJK and Balochistan. The total amount of additional funding required for meeting FP needs in Balochistan, AJK, GB, and FATA is $\$ 11.7$ million.

\section{Provide vouchers for travel and out-of-pocket expenses to the poorest women}

We know that in every province and region, it is women belonging to the poorest groups who are most likely to suffer from unwanted pregnancies. The poorest women often bear additional costs of transport and other out-of-pocket costs due to their remote settings. These costs are also harder to absorb in the limited budgets of poor households even if services are available in the vicinity. As can be seen in Table 3,61\% of the poorest women have unmet need for modern contraceptive services, which is much higher than the average of $52 \%$ in the general population.

Table 4: Unmet need for modern contraception in Pakistan, by income quintiles, 2017

\begin{tabular}{|cc|c|c|}
\hline \multirow{2}{*}{\begin{tabular}{|}
\multirow{2}{*}{ Income quintiles } \\
\cline { 2 - 4 }
\end{tabular}} & \multicolumn{2}{|c|}{$\begin{array}{c}\text { Married women who want to avoid pregnancy } \\
\text { and are not using modern contraception }\end{array}$} \\
\cline { 2 - 4 } & 1 & No. (in millions) & $\%$ \\
\hline Poorest & 2 & 1.6 & 61 \\
\hline 3 & 1.8 & 54 \\
\hline Wealthiest & 5 & 1.8 & 50 \\
\hline Total & 1.6 & 47 \\
\hline
\end{tabular}

Source: Sundaram, A., Hussain, R., Sathar, Z., Hussain, S., Pliskin, E., \& Weissman, E. (2019). Adding It Up: Costs and Benefits of Meeting the Contraceptive and Maternal And Newborn Health Needs of Women in Pakistan, New York: Guttmacher Institute.

The Demographic and Health Surveys rank individuals according to their household assets and divide the population into five groups of equal size (quintiles) to capture relative differences in wealth.

NOTE: Numbers and percentages may not add to totals (here or in the text) because of rounding.

We propose that the poorest women in all areas be a special focus in additional family planning investments, specifically through vouchers that enable them to reach FP services. The Benazir Income Support Program (BISP), which systematically maintains a registry of the poorest women, would be a perfect vehicle for such a subsidy. In fact, provision of such vouchers is being piloted in southern Punjab for a potential population of 20,000 BISP beneficiaries. While the pilot scheme covers both private sector service provider fees and other out-of-pocket expenses incurred by beneficiaries in obtaining FP services, our proposal is to provide vouchers directly to poor women themselves to help them cover the costs of traveling long distances to access family planning services. We propose that each voucher should allow for four trips to FP service delivery points at Rs. 500 per trip, covering travel and other out-of-pocket expenses, excluding services, which we anticipate will improve through other subsidies to the less served regions. The total payment for four trips amounts to about $\$ 12$. At this rate, the total cost of reaching the 1.6 million poorest women with unmet need amounts to $\$ 19.2$ million. 


\section{Conclusions}

Additional financing for family planning is strongly justified, not only to increase contraceptive prevalence, reduce unmet need for family planning, and avert millions of unwanted pregnancies, but also to reduce maternal mortality and effect improvements in other spheres of development.

As a safeguard against unintended fertility, family planning can contribute to national savings in multiple ways. The total additional ask per year is $\$ 93$ million or 40 cents per capita—a meagre investment that promises huge dividends.

But alongside additional funding, spending must be made more effective by strengthening the $\mathrm{DOH}$ to mainstream family planning services since it is vastly underperforming despite its vast network of clinics and Lady Health Workers. Its relevance and mandate for providing family planning services to the poorest families and those living in remote areas is critical. At the very least, the Rs. 10 billion (\$67 million) Population Fund should be entirely allocated for this purpose.
The private sector may be expected to continue to cater to sections of the society that can afford to pay for its services, whether provided at full price by commercial channels or as subsidized services by non-governmental and social marketing organizations. The second set of priorities comprises the regions that have much smaller budgets and therefore face greater difficulty in filling funding gaps for FP, particularly FATA, GB and Balochistan. Some, like AJK, are performing better with their outlay despite smaller budgets. This funding should again go for LHWs, staff of static clinics, and contraceptives for the health sector. The approximate shortfall for these areas is $\$ 11.7$ million.

The third priority is to focus on the poorest women across Pakistan whose unmet need for family planning is the highest. We estimate that the approximately $\mathbf{1 . 6}$ million poorest women could be provided subsidies of about Rs. 2,000 for travel and other out-of-pocket expenses incurred in reaching FP services. The total amount would be $\$ 19.2$ million. Notably, the vouchers proposed for these women do not cover provider fees, as we assume that the subsidies recommended above will improve provision of free or low-cost public sector family planning services in their regions. 


\section{References}

1. In this brief, \$ refers to United States dollars.

2. FP2020. (2017).SSummary of Commitments. Available at: http://www.familyplanning2020.org/sites/default/files/FP_Summit_2017_Commitment_Summary_Update-V18-Clean_7.pdf;

3. Schäferhoff, M., van Hoog, S., Martinez, S., Fewer, S., and Yamey, G. (2019). Funding for sexual and reproductive health and rights in low- and middle-income countries: threats, outlook and opportunities. The Partnership for Maternal, Newborn \& Child Health, Geneva: Switzerland.

4. FP2020. Women at the center 2018-2019. Available at: http://progress.familyplanning2020.org/sites/all/themes/custom/progressreport/pdf/FP2020_2019Report_ WEB.pdf.

5. UN DESA. (2019). Family Planning and the 2030 Agenda for Sustainable Development: Data Booklet. (ST/ESA/ SER.A/429). United Nations, Department of Economic and Social Affairs, Population Division.

6. Kantorová, V., Wheldon, M. C., Ueffing, P., E Dasgupta, A. N. Z. (2020). Estimating progress towards meeting women's contraceptive needs in 185 countries: A Bayesian hierarchical modelling study. PLoS medicine, 17(2), e1003026.

7. Sully, E. A., Biddlecom, A., Darroch, J. E., Riley, T., Ashford, L. S., Lince-Deroche, N., ... E Murro, R. (2020). Adding It Up: Investing in Sexual and Reproductive Health, 2019. New York, NY: Guttmacher Institute.

8. Ibid.

9. Miller, N., Weinberger, M., and Skibiak, J. (2018). Global Contraceptive Commodity Gap Analysis. Reproductive Health Supplies Coalition, Brussels.

10. Sully, E. A., Biddlecom, A., Darroch, J. E., Riley, T., Ashford, L. S., Lince-Deroche, N., ... E Murro, R. (2020). Adding It Up: Investing in Sexual and Reproductive Health, 2019. New York, NY: Guttmacher Institute.

11. Starrs, A. M., Ezeh, A. C., Barker, G., Basu, A., Bertrand, J. T., Blum, R., ... E Sathar, Z. A. (2018). Accelerate progress-sexual and reproductive health and rights for all: report of the Guttmacher-Lancet Commission. The Lancet, 391, 2642-2692.

12. Sully, E. A., Biddlecom, A., Darroch, J. E., Riley, T., Ashford, L. S., Lince-Deroche, N., ... E Murro, R. (2020). Adding It Up: Investing in Sexual and Reproductive Health, 2019. New York, NY: Guttmacher Institute.

13. Kohler, H. P., E Behrman, J. R. (2014). Benefits and costs of the population and demography targets for the post-2015 development agenda. Copenhagen Consensus Center, Population and Demography Assessment Paper.

14. USAID Health Policy Initiative. (2009). Family planning and the MDGs: Saving lives, saving resources. USAID Health Policy Initiative. Available at: http:// www.healthpolicyinitiative.com/index.cfm?ID=publications $\mathcal{g}$ get $=$ pubIDEpubID=788.

15. Starrs, A. M., Ezeh, A. C., Barker, G., Basu, A., Bertrand, J. T., Blum, R., ... E Sathar, Z. A. (2018). Accelerate progress-sexual and reproductive health and rights for all: report of the Guttmacher-Lancet Commission. The Lancet, 391, 2642-2692.

16. UN Population Division. (2009). “What Would It Take to Accelerate Fertility Decline in the Least Developed Countries?" Policy Brief 2009/1, United Nations, New York.

17. Law and Justice Commission of Pakistan and Ministry of National Health Services, Regulations and Coordination, Government of Pakistan (2018). National Symposium on Alarming Population Growth: A Call for Action, Islamabad, Pakistan: UNFPA and Population Council.

18. Malik, M. A., Nahyoun, A. S., Rizvi, A., Bhatti, Z. A., \& Bhutta, Z. A. (2017). Expenditure tracking and review of reproductive maternal, newborn and child health policy in Pakistan. Health Policy and Planning, 32(6), 781-790.

19. Pakistan Bureau of Statistics. (2018). National Health Accounts Pakistan 2015-16. Islamabad: Government of Pakistan, Statistics Division, Pakistan Bureau of Statistics.

20. TRF. (2012a). A Report on Costing Essential Package of Health Services Primary Health Care Facilities in Sindh, Pakistan: Technical Resource Facility.

21. TRF. (2012b). A Report on Costing Essential Package of Health Services Primary Health Care Facilities in Punjab, Pakistan: Technical Resource Facility.

22. RF. (2012c). A Report on Costing Essential Package of Health Services Primary Health Care Facilities in Khyber Pakhtunkhwa, Pakistan: Technical Resource Facility.

23. WHO. (2003). Guide to producing national health accounts with special applications for low-income and middle-income countries. World Health Organization. Geneva: Switzerland.

24. Darroch, J. E., Singh, S., E Weissman, E. (2016). Adding It Up: The Costs and Benefits of Investing in Family Planning and Maternal and Newborn Health 2014Estimation Methodology, New York: Guttmacher Institute.

25. Darroch, J. E. (2018). Adding It Up: Investing in Contraception and Maternal and Newborn Health, 2017 Estimation Methodology. New York: Guttmacher Institute.

26. Private sector expenditures on family planning are even harder to estimate than public sector spending. Importantly, the National Health Accounts do indicate that over $60 \%$ of MNH expenditure, including FP, is borne out-of-pocket by families for services in the private sector or to supplement public sector costs. We also know that the private sector is an important source of family planning from the Pakistan Demographic and Health Survey (PDHS) 2017-18, which reports that $57 \%$ of contraceptive users in Pakistan procure services and commodities from the private sector, including the private medical sector (42\%), shops (11\%), and other sources such as family physicians and hakims $(4 \%)$. In comparison, $44 \%$ of pregnant women utilize the private sector for deliveries and $49 \%$ for antenatal care.

27. Further details of the complete methodology are available at https://www.guttmacher.org/sites/default/files/report_downloads/adding-it-up-pakistan-methodology-appendix.pdf and https://www.guttmacher.org/report/adding-it-up-meeting-contraceptive-MNCH-needs-Pakistan.

28. Sathar, Z. A. (2013). Family planning: a missing priority in Pakistan's health sector? The Lancet, 381(9884), pp2140-2141.

29. Rashida, G., I. Kamran, M. Khalil, Z. Tasneem, R. Niazi, M. Khan, and T. Parveen. 2017. Increasing Access to Reproductive Health Care through Improved Service Delivery. Islamabad: Population Council. 